\title{
Effects of Software Agents on Decision Support System
}

\author{
Aquibjaved Momin ${ }^{1}$, Varun Nirantar ${ }^{2}$, Abhijeet Zagade ${ }^{3}$, Abhishek Deshmukh $^{4}$ \\ ${ }_{1,2,3,4}$ (Department of Information Technology, Sinhgad College of Engineering/ University of Pune \\ ,Maharashtra, India)
}

\begin{abstract}
Software agents are a major innovation in how people use information systems, and they have parallels with how Decision Support Systems (DSS) support human decision-making. A DSS approach to the development of software agents suggests a highly interactive and flexible interface between the agent and its user, and addresses some potential barriers to the successful adoption of agent technologies. Within a DSS model, agents can be classified as providing search, choice or interface support. Each of these classifications uses techniques originating from separate disciplines and requires different performance measures. We use a real estate agent as a metaphor to examine the descriptive, procedural and semantic knowledge bases that agents can use to support search and choice activities in an e-commerce domain.
\end{abstract}

Keywords - Decision Support System, e-Commerce, e-publishing, Information Retrieval, Knowledgeable Agents, Web mining .

\section{INTRODUCTION}

Software agents are computer programs that run in the background and perform tasks autonomously, as delegated by the user. Although there has been much research on this topic, usable software agents are at an early stage of development, and are only now starting to appear in real applications. A fruitful application area for software agents is in the area of electronic commerce where agents can help buyers and sellers deal with the flood of information that can be exchanged and processed. Related research has examined how agents can support purchasing activities using traditional buyer behavior models [1][2] and identified basic knowledge requirements for agents supporting integrated electronic commerce systems [3]. A fruitful application area for software agents is in the area of electronic commerce (e-commerce) where agents can help buyers and sellers deal with the flood of information that can be exchanged and processed. Here we explain how examining of ecommerce as a process - a complex series of decision-making tasks is done. Here we also explain how the research is limited to software agents that are classified under the Decision Support Systems (DSS) approach. It does not address agents or agent systems that are completely hidden from the user. There must be at least an initial interaction between the user and the agent where the user "delegates" an action or task to the agent. It also does not address agents whose primary function is to simulate realistic human behavior and engage in a "social" interaction with the user.

The rate of innovation in e-commerce means that developers need to be able to move quickly from research to commercially viable products. Answering these questions can provide guidance to managers who are considering agent technology and its potential for facilitating e-commerce. The answers can also provide direction for researchers in IS and other disciplines. An introduction to a research area would normally start with a definition. However, there is no single definition of a software agent that has gained acceptance. This is not unexpected in an emerging field with a number of contributing disciplines. Bradshaw (1997) argues that there are two approaches to defining a software agent[3]: 1) as a description, and 2) as an ascription. Most of the definitions proposed in the literature are of Bradshaw's "agent as a description" form[4]. The use of e-commerce is growing rapidly in both the business-to-consumer (B2C) and business-to-business (B2B) environments. Bradshaw (1997) argues that there are two approaches to defining a software agent:1) as a description, and 2) as an ascription[6]. Most of the definitions proposed in the literature are of Bradshaw's "agent as a description" form. In these definitions, various attributes are listed to describe what is meant by the term "agent", often including some or all of: autonomous, persistent, mobile, intelligent, learning, responsive, pro-active, communicating, social, and rational. These characteristics are often used in defining sub-categories of software agents, such as mobile agents, learning agents, and "multi-agent societies" of social and communicating agents. An agent is defined "as an ascription" through an attribution by the user; if the user believes that he or she has delegated a task to the software entity, it is an agent. In this case, an agent is seen as a black box, where the user desires results but does not know (or want to know) how the agent is performing a task. 


\section{SOFTWARE AGENTS}

In computer science, a software agent is a computer program that acts for a user or other program in a elationship of agency, which derives from the Latin agere (to do): an agreement to act on one's behalf. Such "action on behalf of" implies the authority to decide which, if any, action is appropriate.

Related and derived concepts include intelligent agents (in particular exhibiting some aspect of artificial intelligence, such as learning and reasoning), autonomous agents (capable of modifying the way in which they achieve their objectives), distributed agents (being executed on physically distinct computers), multiagent systems (distributed agents that do not have the capabilities to achieve an objective alone and thus must communicate), and mobile agents (agents that can relocate their execution onto different processors).[7]

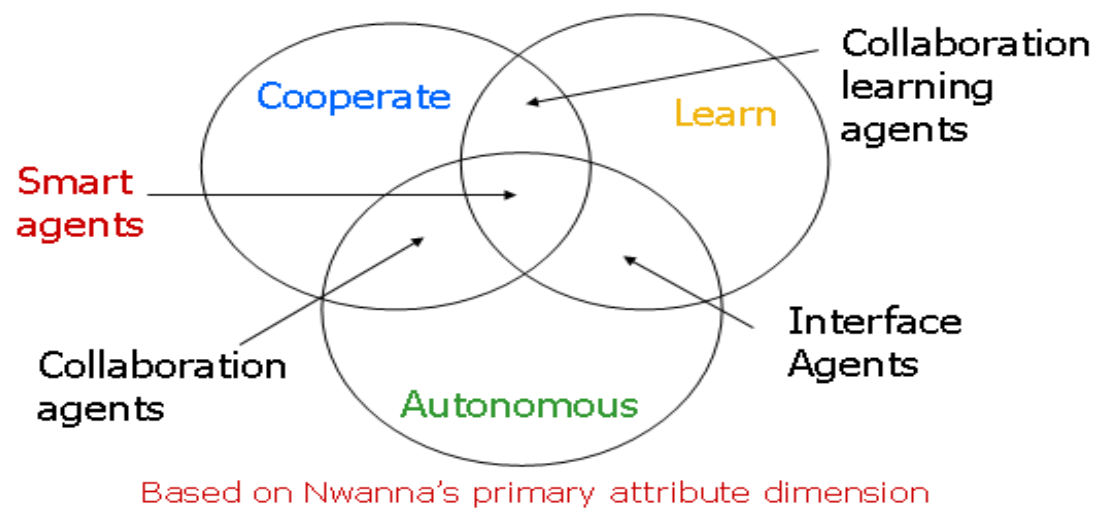

Fig1: Nwana's Category of Software Agent

The basic attributes of a software agent are that agents

- are not strictly invoked for a task, but activate themselves,

- may reside in wait status on a host, perceiving context,

- may get to run status on a host upon starting conditions,

- do not require interaction of user,

The term "agent" describes a software abstraction, an idea, or a concept, similar to OOP terms such as

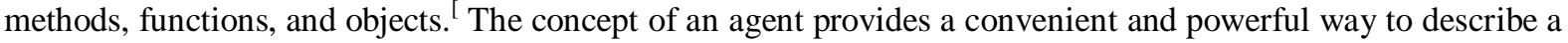
complex software entity that is capable of acting with a certain degree of autonomy in order to accomplish tasks on behalf of its host. But unlike objects, which are defined in terms of methods and attributes, an agent is defined in terms of its behavior.

\subsection{Buyer agents (shopping bots)}

Buyer agents travel around a network (i.e. the internet) retrieving information about goods and services. These agents, also known as 'shopping bots', work very efficiently for commodity products such as CDs, books, electronic components, and other one-size-fits-all products.

\subsection{User agents (personal agents)}

User agents, or personal agents, are intelligent agents that take action on your behalf. In this category belong those intelligent agents that already perform, or will shortly perform, the following tasks:

- Check your e-mail, sort it according to the user's order of preference, and alert you when important emails arrive.

- Play computer games as your opponent or patrol game areas for you.

- Assemble customized news reports for you. There are several versions of these, including CNN.[8]

- Find information for you on the subject of your choice. 


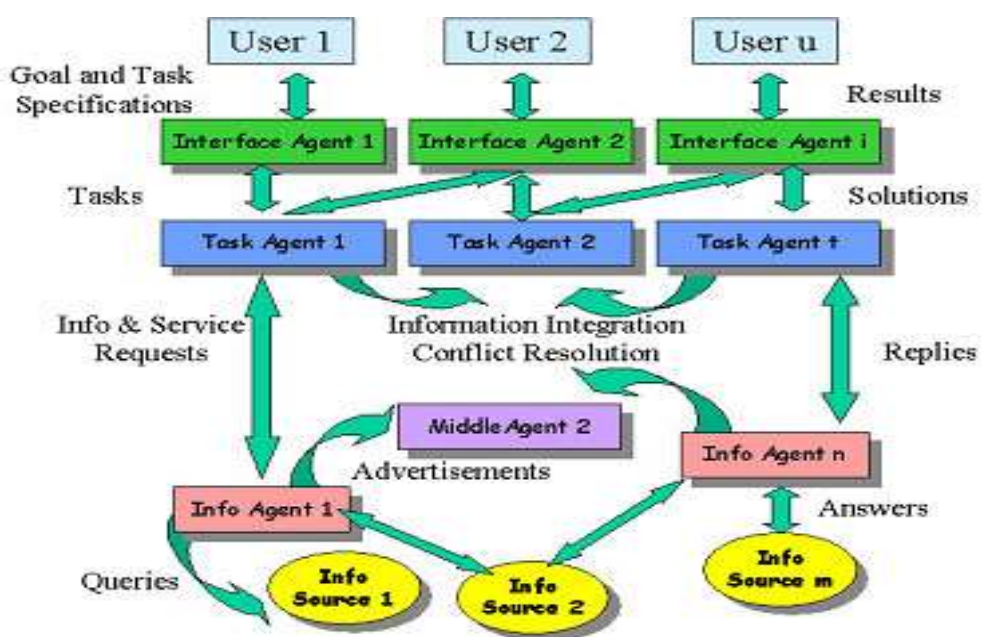

Fig 2: Working of software agents

- Fill out forms on the Web automatically for you, storing your information for future reference

- Scan Web pages looking for and highlighting text that constitutes the "important" part of the information there

- "Discuss" topics with you ranging from your deepest fears to sports

- Facilitate with online job search duties by scanning known job boards and sending the resume to opportunities.

- Profile synchronization across heterogeneous social networks

Monitoring and Surveillance Agents are used to observe and report on equipment, usually computer systems. The agents may keep track of company inventory levels, observe competitors' prices and relay them back to the company, watch stock manipulation by insider trading and rumors, etc. For example, NASA's Jet Propulsion Laboratory has an agent that monitors inventory, planning, and scheduling equipment ordering to keep costs down, as well as food storage facilities.

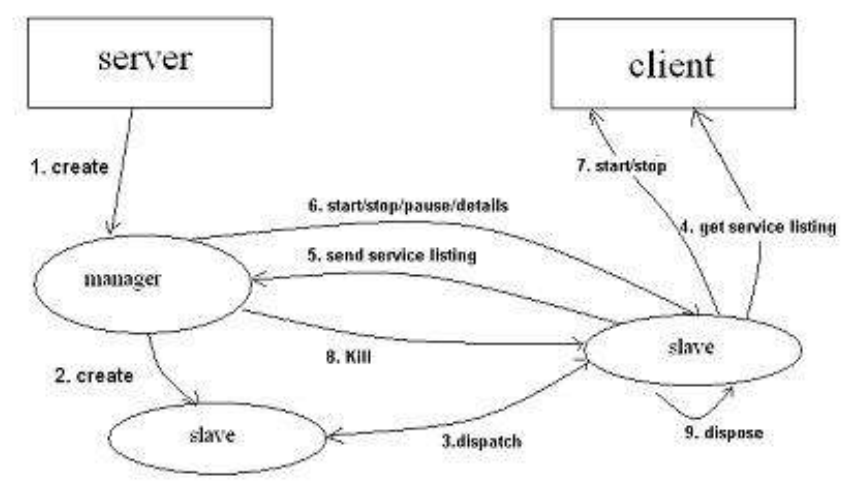

Fig 2: service monitoring

The agents monitor the status of assets (ammunition, weapons available, platforms for transport, etc.) and receive Goals (Missions) from higher level agents. The Agents then pursue the Goals with the Assets at hand, minimizing expenditure of the Assets while maximizing Goal Attainment. [9]

\subsection{Data-mining agents}

This agent uses information technology to find trends and patterns in an abundance of information from many different sources. The user can sort through this information in order to find whatever information they are seeking. A data mining agent operates in a data warehouse discovering information. A 'data warehouse' brings together information from lots of different sources. "Data mining" is the process of looking through the data warehouse to find information that you can use to take action, such as ways to increase sales or keep customers who are considering defecting. 


\subsection{Networking and communicating agents}

Some other examples of current intelligent agents include some spam filters, game bots, and server monitoring tools. Search engine indexing bots also qualify as intelligent agents.

- User agent - for browsing the World Wide Web

- Mail transfer agent - For serving E-mail, such as Microsoft Outlook. Why? It communicates with the POP3 mail server, without users having to understand POP3 command protocols. It even has rule sets that filter mail for the user, thus sparing them the trouble of having to do it themselves.

- SNMP agent

- In Unix-style networking servers, httpd is an HTTP daemon that implements the HyperText Transfer Protocol at the root of the World Wide Web.

\section{E-COMMERCE}

Electronic commerce or e-commerce refers to a wide range of online business activities for products and services. It also pertains to "any form of business transaction in which the parties interact electronically rather than by physical exchanges or direct physical contact." E-commerce is usually associated with buying and selling over the Internet, or conducting any transaction involving the transfer of ownership or rights to use goods or services through a computer-mediated network.[6]

- What are the different types of e-commerce?

The major different types of e-commerce are: business-to-business (B2B); business to-consumer (B2C); business-to-government (B2G); consumer-to-consumer (C2C); and mobile commerce (m-commerce).

- What is B2B e-commerce?

$\mathrm{B} 2 \mathrm{~B}$ e-commerce is simply defined as e-commerce between companies. This is the type of e-commerce that deals with relationships between and among businesses. About $80 \%$ of e-commerce is of this type, and most experts predict that $\mathrm{B} 2 \mathrm{~B}$ ecommerce will continue to grow faster than the $\mathrm{B} 2 \mathrm{C}$ segment. The $\mathrm{B} 2 \mathrm{~B}$ market has two primary components: e-frastructure and e-markets. E-markets are simply defined as Web sites where buyers and sellers interact with each other and conduct transactions. The more common B2B examples and best practice models are IBM, Hewlett Packard (HP), Cisco and Dell. Cisco, for instance, receives over 90\% of its product orders over the Internet.

- What is $\mathrm{B} 2 \mathrm{C}$ e-commerce?

Business-to-consumer e-commerce, or commerce between companies and consumers, involves customers gathering information; purchasing physical goods (i.e., tangibles such as books or consumer products) or information goods (or goods of electronic material or digitized content, such as software, or e-books); and, for information goods, receiving products over an electronic network.

- What is $\mathrm{B} 2 \mathrm{G}$ e-commerce?

Business-to-government e-commerce or B2G is generally defined as commerce between companies and the public sector. It refers to the use of the Internet for public procurement, licensing procedures, and other government-related operations. This kind of e-commerce has two features: first, the public sector assumes a pilot/leading role in establishing e-commerce; and second, it is assumed that the public sector has the greatest need for making its procurement system more effective. [10]

- What is $\mathrm{C} 2 \mathrm{C}$ e-commerce?

Consumer-to-consumer e-commerce or $\mathrm{C} 2 \mathrm{C}$ is simply commerce between private individuals or consumers. This type of e-commerce is characterized by the growth of electronic marketplaces and online auctions, particularly in vertical industries where firms/businesses can bid for what they want from among multiple suppliers. It perhaps has the greatest potential for developing new markets. Consumer-to-business (C2B) transactions involve reverse auctions, which empower the consumer to drive transactions. A concrete example of this when competing airlines gives a traveler best travel and ticket offers in response to the traveler's post that she wants to fly from New York to San Francisco. There is little information on the relative size of global C2C e-commerce. However, $\mathrm{C} 2 \mathrm{C}$ figures of popular $\mathrm{C} 2 \mathrm{C}$ sites such as eBay and Napster indicate that this market is quite large. These sites produce millions of dollars in sales every day.[11]

\subsection{Agents}

\section{DECISION SUPPORT SYSTEMS}

DSS are commonly considered to include a data subsystem, a model subsystem and a dialogue subsystem. Turban [7] suggests that AI can be embedded into DSS to support the model, data or dialogue subsystems, the complete system, or the user. We propose a classification of agents according to whether they support search Functions through the data subsystem, choice functions through the model subsystem, or interface functions through the dialogue subsystem. 


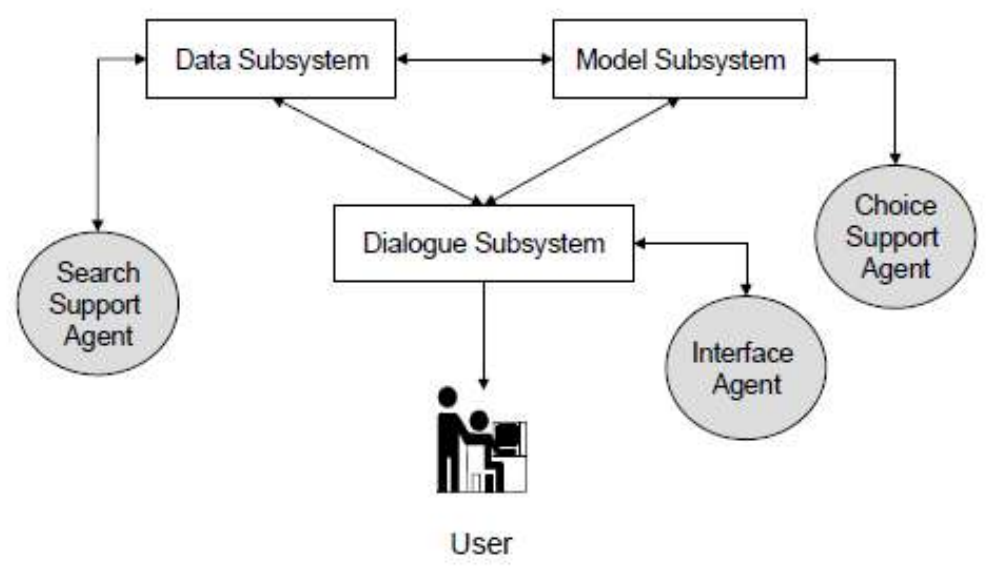

Fig 3: Agents in a Decision Support System[7]

We can distinguish between search, choice and interface agents according to the disciplines from which they borrow their techniques and how their performance should be measured. Table 2 summarizes these disciplines and measures. Agents that support the search function use techniques and measures developed within the information retrieval (IR) community. Agents that support the choice function borrow their techniques from economics, psychology, management science and other disciplines that describe how people make choices between alternative and how to improve decision quality.[12]

Table 1: Agent Reference Disciplines and Measures

\begin{tabular}{|l|l|l|}
\hline Type of Agent & Reference Discipline(s) & $\begin{array}{l}\text { Potential Performance } \\
\text { Measures }\end{array}$ \\
\hline SEARCH SUPPORT & Information Retrieval & $\begin{array}{l}\text { Precision } \\
\text { Recall }\end{array}$ \\
\hline CHOICE SUPPORT & $\begin{array}{l}\text { Decision theory from: } \\
\text { Economics } \\
\text { Psychology } \\
\text { Management Science }\end{array}$ & $\begin{array}{l}\text { Consistency of decisions } \\
\text { Compare choice to optimal } \\
\text { Amount of information used or } \\
\text { processed } \\
\text { Time to make decision }\end{array}$ \\
\hline INTERFACE SUPPORT & Human Computer Interaction & $\begin{array}{l}\text { Usability measures such as: } \\
\text { User satisfaction } \\
\text { Errors } \\
\text { Learning time }\end{array}$ \\
\hline
\end{tabular}

\subsection{A Model of Search}

Figure 4 shows a basic search model that contains an information source and its representation, an information need and its representation, and a method for comparing these representations. Both the information source and the information need may change over time. Information retrieval deals with a "static" set of sources and a "dynamic" set of one-time needs (queries). Information filtering deals with "dynamic" sources and a "static" need (a profile) [12]. Information sources can be unstructured (e.g. full text), semi-structured (e.g. integrated catalogues) or structured (e.g. databases), and the degree of structure will affect the kind of representation used. Full text sources may be represented by sets of index terms. Catalogue items may be represented by minimal information (e.g. a product name and a supplier) with a link to the full information source. 


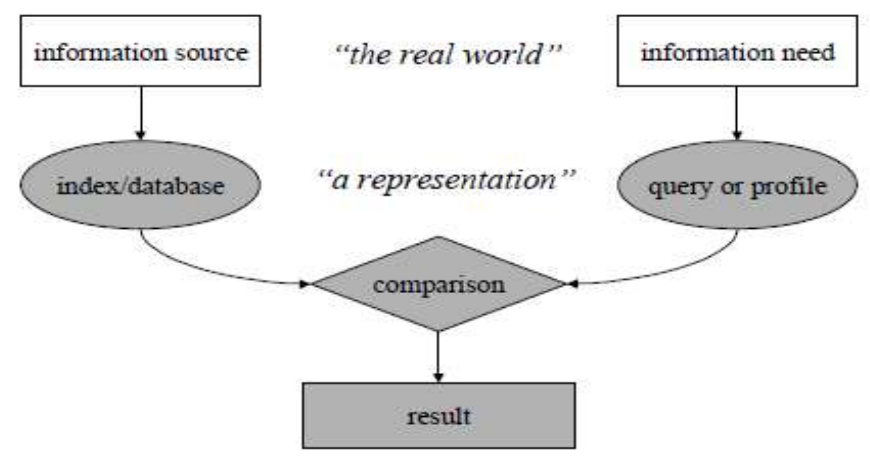

Fig 4: Model of Search[12]

\subsection{Model of Choice}

In the real world, the choice problem can be described as interrelated sets of alternatives, criteria and consequences that are processed and analyzed by the decision-maker [13]. To model the problem (see Figure 5) each alternative can be represented by a set of variables. Parameters are set to represent the selected criteria and any assumptions about the problem situation. A decision model is used to process each alternative, returning a result that represents the consequences of that choice. Prescriptive models compare results and determine the best choice of alternatives. Descriptive models present the results associated with each alternative to the decision-maker.
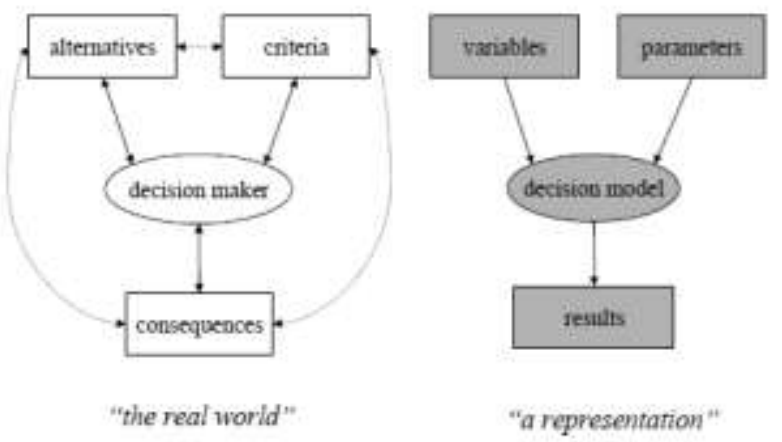

Fig 5: Model of Choice[13]

4.4 Knowledgeable Agents for Search

\begin{tabular}{|l|l|l|l|}
\hline $\begin{array}{l}\text { Type of } \\
\text { Knowledge }\end{array}$ & $\begin{array}{l}\text { Knowledge } \\
\text { Requirements }\end{array}$ & $\begin{array}{l}\text { Design Challenges } \\
\text { DEcation of } \\
\text { information sources }\end{array}$ & $\begin{array}{l}\text { Distributed sources and } \\
\text { the "connection problem" } \\
\text { \& Research Areas }\end{array}$ \\
\cline { 2 - 4 } & $\begin{array}{l}\text { Multi-agent architectures } \\
\text { with directories, } \\
\text { matchmakers, and } \\
\text { brokers }\end{array}$ \\
\hline & $\begin{array}{l}\text { Data extracted from } \\
\text { information sources }\end{array}$ & $\begin{array}{l}\text { Heterogeneous sources } \\
\text { with varying levels of } \\
\text { structure }\end{array}$ & $\begin{array}{l}\text { XML coding within } \\
\text { information sources }\end{array}$ \\
\cline { 2 - 4 } & Data describing \\
information needs & Reduce profiling effort & $\begin{array}{l}\text { Use of proxy information, } \\
\text { learning systems and } \\
\text { collaborative systems }\end{array}$ \\
\hline PROCEDURAL[15] & Search strategies & $\begin{array}{l}\text { Distributed, dynamic } \\
\text { environment }\end{array}$ & $\begin{array}{l}\text { Adaptive search } \\
\text { strategies that optimize } \\
\text { time, cost or quality of } \\
\text { search. }\end{array}$ \\
\cline { 2 - 4 } & Creating representations & $\begin{array}{l}\text { Heterogeneous sources } \\
\text { and users }\end{array}$ & $\begin{array}{l}\text { Information extraction } \\
\text { and query formation } \\
\text { using linguistic analysis } \\
\text { and natural language } \\
\text { processing }\end{array}$ \\
\hline
\end{tabular}




\begin{tabular}{|l|l|l|l|}
\hline & Matching algorithms & $\begin{array}{l}\text { Balance between recision } \\
\text { and recall }\end{array}$ & $\begin{array}{l}\text { Probabilistic techniques } \\
\text { for information retrieval }\end{array}$ \\
\hline \multirow{3}{*}{ SEMANTIC } & Ontology & Standardization & $\begin{array}{l}\text { Base and domain } \\
\text { ontology development }\end{array}$ \\
\cline { 2 - 4 } & $\begin{array}{l}\text { Communications } \\
\text { protocols }\end{array}$ & $\begin{array}{l}\text { Open systems, } \\
\text { heterogeneous } \\
\text { agents }\end{array}$ & KQML \\
\hline
\end{tabular}

\subsection{Knowledgeable Agents for Choice Support}

\begin{tabular}{|c|c|c|c|}
\hline $\begin{array}{l}\text { Type of } \\
\text { Knowledge }\end{array}$ & $\begin{array}{l}\text { Knowledge } \\
\text { Requirements }\end{array}$ & Design Challenges & $\begin{array}{l}\text { Applicable Technologies } \\
\text { \& Research Areas }\end{array}$ \\
\hline \multirow{3}{*}{ DESCRIPTIVE[16] } & Attributes to describe & alternatives & $\begin{array}{l}\text { Restructuring Base and } \\
\text { domain ontology }\end{array}$ \\
\hline & \multirow[t]{2}{*}{$\begin{array}{l}\text { Data extracted from } \\
\text { information sources }\end{array}$} & Constructive Choice & $\begin{array}{l}\text { Learning and interactive } \\
\text { systems }\end{array}$ \\
\hline & & Situational factors & $\begin{array}{l}\text { Case-based reasoning } \\
\text { and } \\
\text { learning }\end{array}$ \\
\hline \multirow{5}{*}{ PROCEDURAL[17][18] } & \multirow[t]{2}{*}{$\begin{array}{l}\text { Decision models and } \\
\text { management } \\
\text { algorithms }\end{array}$} & $\begin{array}{l}\text { Individual preferences } \\
\text { and use of more than one } \\
\text { model }\end{array}$ & $\begin{array}{l}\text { Multi-model systems } \\
\text { and model management }\end{array}$ \\
\hline & & Sequential decisions & $\begin{array}{l}\text { Dynamic decision- } \\
\text { making models }\end{array}$ \\
\hline & Creating representations & $\begin{array}{l}\text { Heterogeneous sources } \\
\text { and users }\end{array}$ & $\begin{array}{l}\text { Information extraction } \\
\text { and query formation } \\
\text { using linguistic analysis } \\
\text { and natural language } \\
\text { processing }\end{array}$ \\
\hline & $\begin{array}{l}\text { Process and workflow } \\
\text { knowledge }\end{array}$ & Adaptive processes & $\begin{array}{l}\text { Learning and reasoning } \\
\text { systems }\end{array}$ \\
\hline & Negotiating strategies & $\begin{array}{l}\text { Non-cooperative } \\
\text { environments and multi- } \\
\text { dimensional solution } \\
\text { spaces }\end{array}$ & $\begin{array}{l}\text { Learning systems using } \\
\text { probabilistic networks or } \\
\text { genetic algorithms }\end{array}$ \\
\hline \multirow[t]{2}{*}{ SEMANTIC } & Negotiation protocols & $\begin{array}{l}\text { Mechanisms that } \\
\text { encourage appropriate } \\
\text { agent behavior }\end{array}$ & $\begin{array}{l}\text { Research from micro- } \\
\text { economics and game } \\
\text { theory }\end{array}$ \\
\hline & Transaction protocols & Standardization & $\begin{array}{l}\text { Adapting EDI-type } \\
\text { messages for agent } \\
\text { systems using KQML }\end{array}$ \\
\hline
\end{tabular}

\section{CONCLUSION}

A Software agents may be an important innovation in how people deal with distributed, complex and ubiquitous systems [19] such as those envisioned for e-commerce. We have shown how a DSS approach to software agents leads us towards flexible and interactive systems that accommodate the capabilities of AI systems and adjust to the user's individual and changing needs. The DSS approach also suggests a classification system according to whether agents support search, choice or interface functions. The techniques used in these functions have different reference disciplines, and suggest that agent performance should be measured differently in each function. Future research will be directed at determining whether a system image that uses these functional classifications can help the user develop an improved conceptual model of the agent system. Similarly, we would like to determine if function-specific measures could improve the way agent systems are evaluated. Within the DSS framework, we have provided examples of the knowledge bases that agents may use to duplicate the services of a human agent in search and choice functions. We identified some of the many design challenges that these systems will encounter and highlighted some promising research areas. Some of the design challenges can best be addressed through continuing multidisciplinary efforts. The capabilities of new information and communications technologies are redirecting research efforts in many related areas. The Information Sciences community continues to work on more effective linguistic analysis and probabilistic 
techniques for information retrieval. Management Science can contribute with innovative and dynamic decision models, economists by continuing to develop and adapt mechanisms for non-cooperative environments and multidimensional solution spaces. Computer Science will need to develop, design and implement the systems architectures where agents can interact. Continued multidisciplinary communication and collaboration will be important in meeting these challenges. Other design challenges reflect the need for effective industry cooperation and coordination. Base and domain ontology and transaction protocols require broad support across and within industry groups. History tells us that the market will ultimately determine the success of XML, KQML and other potential standards.

Norman cautions that the main problems facing widespread agent implementation will be "social" and not "technical". In order to develop trust in the agent's capabilities, users will need to understand what the agent is doing, and receive appropriate reassurance that it is behaving as expected [5]. From the user's point of view, agent performance in e-commerce will not be likely be satisfactory until we can develop rich user profiles and incorporate relevant situational factors and the user may have to play an active role while this knowledge is acquired. Constructive choice theories and individual decision-making preferences suggest that more than one decision model should be available and that the user may need to interact with the system in order to choose the model that they are comfortable with for the given task. The DSS approach to software agent development and design addresses these challenges by promoting highly interactive, user- entered, system.

\section{REFERENCES}

[1] Chavez, A. and P. Maes, "Kasbah: An Agent Marketplace for Buying and Selling Goods," First International Conference on the Practical Application of Intelligent Agents and Multi-Agent Technology, London, UK, April 1996.

[2] Nissen, M. E., "Procurement Revolution with Intelligent Agent Technology," PRACTIX, December 1999. http://www.capsresearch.org/research/best-practices.html. (Accessed January 22, 2000.)

[3] Wang, S., “Analyzing Agents for Electronic Commerce," Information Systems Management, 16(Winter): 40-47, 1999.

[4] Genesereth, M. J., "An Agent-based Framework for Interoperability," Software Agents, J. M. Bradshaw (ed.), AAAI Press/MIT Press, Menlo Part, CA, 1997

[5] Norman, D. A., "How People Might Interact with Agents," Software Agents, J. M. Bradshaw (ed.), AAAI Press/The MIT Press, Menlo Park, CA, 1997.

[6] Malone, T., K. R. Grant and K.-Y. Lai, "Agents for Information Sharing and Coordination: A History and Some Reflections," Software Agents, J. M. Bradshaw (ed.), AAAI Press / The MIT Press, Menlo Park, CA, 1997.

[7] Turban, E., Decision Support and Expert Systems, MacMillan, New York, NY, 1988.

[8] Wooldridge, M., "Intelligent Agents," Multiagent Systems, G. Weiss (ed.), MIT Press, Cambridge, MA, 1999

[9] Siskos, Y. and A. Spyridakos, "Intelligent multicriteria decision support: Overview and perspectives," European Journal of Operational Research, 113: 236-246, 1999.

[10] Turing, A. M., "Computing Machinery and Intelligence," MIND - A quarterly review of Psychology and Philosophy, LIX (236), October 1950. http://www.abelard.org/turpap/turpap.htm. (Accessed August 10, 1999.)

[11] Davis, R., H. Shrobe and P. Szolovits, "What is Knowledge Representation?" AI Magazine, 14(1): 17-33, 1993. http://medg.lcs.mit.edu/ftp/psz/k-rep.html. (Accessed August 10, 1998.)

[12] Belkin, N. and W. B. Croft, "Information Filtering and Information Retrieval: Two Sides of the Same Coin?" Communications of the ACM, 35(12): 29-38, December 1992.

[13] White, D. J., Decision Methodology - A Formalization of the OR Process, John Wiley and Sons, London, UK, 1975.

[14] Ackerman, M., D. Billsus, S. Gafney, S. Hettich, G. Khoo, D. Kim, R. Klefstad, C. Lowe, A. Ludeman, J. Muramatsu, K. Omori, M. Pazzini, D. Semler, B. A. Starr and P. Yap, "Learning Probabilistic User Profiles," AI Magazine, Summer: 47-56, 1997. http://www.ics.uci.edu/ pazzani/Publications/AI-MAG.pdf (Accessed June 5, 1998)

[15] Arocena, G. O., A. O. Mendelson and G. A. Mihaila, "Applications of a Web Query Language," University of Toronto. http://www.cs.toronto.edu/ websq1/www-conf/wsq1/PAPER267.html. (Accessed August 4, 1999.)

[16] Coupey, E., "Restructuring: Constructive Processing of Information Displays in Consumer Choice," Journal of Consumer Research, 21: 83-99, June 1994.

[17] Lesser, V., B. Horling, A. Raja, X. Zhang and T. Wagner, "Resource-Bounded Searches in an Information Marketplace," IEEE Internet Computing, 4(2): 49-58, March - April 2000.

[18] Glushko, R. J., J. M. Tenenbaum and B. Meltzer, “An XML Framework for Agent-based E-commerce,” Communications of the ACM, 42(3): 106-114, March 1999.

[19] Jennings, N. R. and M. Wooldridge, Applications of Intelligent Agents, Springer-Verlag. http://www.cs.umbc.edu/agents/introduction/jennings98.pdf. (Accessed June 17, 1998.) 